\title{
Comparative Effect of Low Temperature on Virulence and Twitching Motility of Ralstonia solanacearum Strains Present in Florida
}

\author{
Ana M. Bocsanczy, Ute C. M. Achenbach, Arianna Mangravita-Novo, Jeanne M. F. Yuen, and David J. Norman
}

First, fourth, and fifth authors: Department of Plant Pathology, University of Florida, IFAS, Mid-Florida Research and Education Center, 2725 Binion Rd., Apopka 32703; second author: Development Lead North-East Europe, Syngenta Agro GmbH, Am Technologiepark 1-5 63477 Maintal, Germany; and third author: Sanford-Burnham Medical Research Institute at Lake Nona 6400 Sanger Road, Orlando, FL 32827. First and second authors contributed equally.

Accepted for publication 15 September 2011.

\begin{abstract}
Bocsanczy, A. M., Achenbach, U. C. M., Mangravita-Novo, A., Yuen, J. M. F., and Norman, D. J. 2012. Comparative effect of low temperature on virulence and twitching motility of Ralstonia solanacearum strains present in Florida. Phytopathology 102:185-194.

Ralstonia solanacearum causes bacterial wilt on a wide range of plant hosts. Most strains of $R$. solanacearum are nonpathogenic below $20^{\circ} \mathrm{C}$; however, Race 3 Biovar 2 (R3B2) strains are classified as quarantine pathogens because of their ability to infect crops, cause disease, and survive in temperate climates. We have identified race 1 biovar 1 Phylotype IIB Sequevar 4 strains present in Florida which were able to infect

determined that strains naturally nonpathogenic at $18^{\circ} \mathrm{C}$ were able to multiply, move in planta, and cause partial wilt when inoculated directly into the stem, suggesting that low temperature affects virulence of strains differently at early stages of infection. Bacterial growth in vitro was delayed at low temperatures, however it was not attenuated. Twitching motility observed on growing colonies was attenuated in nonpathogenic strains at $18^{\circ} \mathrm{C}$, while not affected in the cool virulent ones. Using pilQ as a marker to evaluate the relative expression of the twitching activity of $R$. solanacearum strains, we confirmed that cool virulent strains maintained a similar level of pilQ expression at both temperatures, while in nonpathogenic strains $p i l Q$ was downregulated at $18^{\circ} \mathrm{C}$.
\end{abstract} and produce wilt symptoms on potato and tomato at $18^{\circ} \mathrm{C}$. Moreover they infected tomato plants at rates similar to strains belonging to R3B2. We

Ralstonia solanacearum (Smith 1896) Yabuuchi et al. (48) is the causal agent of bacterial wilt of over 200 host species. The organism is a gram-negative bacterium well adapted to live in subtropical and tropical regions (4). The $R$. solanacearum species complex is composed of a wide diversity of strains with varying degree of virulence to diverse hosts $(10,19,25,34)$. Traditionally, $R$. solanacearum strains have been divided into five races based on host range $(5,16)$, and six biovars based on biochemical properties (14). More recently, $R$. solanacearum strains have been classified in phylotypes and sequevars based on phylogenetic relationships resultant from analysis of the internal transcribed spacer region of the $16 \mathrm{~S}$ rRNA sequence and the endoglucanase (egl) gene, respectively (10); however, none of these classifications can completely describe the diversity of strains for the $R$. solanacearum species complex.

Although $R$. solanacearum is one of the major plant pathogens in tropical and subtropical areas of the world, more recently it has become a recognized problem in temperate regions as well (9). Although there are reports of the pathogen being able to survive at relatively low temperatures for long periods of time $(28,45)$, most of the $R$. solanacearum strains identified to date are nonpathogenic below $20^{\circ} \mathrm{C}(6)$. Strains in the subgroup race 3 biovar 2 (R3B2) can cause bacterial wilt on potatoes at low temperatures common in the highlands of tropical regions (44), and they have survived winters in major potato producing regions in Europe (18). No strain in this group was reported in the United States

Corresponding author: D. J. Norman; E-mail address: djn@ufl.edu

* The $\boldsymbol{e}$-Xtra logo stands for "electronic extra" and indicates that the online version contains two supplemental figures.

http://dx.doi.org/10.1094/PHYTO-05-11-0145

(C) 2012 The American Phytopathological Society
Additional keywords: comparative study, select agent.

until 1999 when an R3B2 strain was detected on geranium cuttings entering the country (21). Since then, $R$. solanacearum R3B2 strains have repeatedly been detected on imported geraniums at different entry point to the United States $(22,47)$, and their spread has been contained. Currently R3B2 strains are not known to be established in the United States.

The ability of some R3B2 strains to infect potato and tomato crops at temperatures below $20^{\circ} \mathrm{C}$, and the potential of being introduced through imported plant material, make them a serious threat to U.S. agriculture. As a preventive measure, R3B2 strains are listed as Select Agent, a designation under the U.S. Agriculture Bioterrorism Protection Act of 2002 (23).

$R$. solanacearum infects the hosts through the roots and ultimately invades the vascular tissues where it multiplies until it blocks the xylem and causes wilting symptoms. The disease process is very complex and involves several stages which are dependent on environmental conditions, physiological state of the pathogen, and the host (15). At the first stage, when strains of virulent $R$. solanacearum present in the soil enter in close contact with the rhizosphere of a host plant, $R$. solanacearum senses specific chemical (49) and energy (50) stimuli, and moves toward the plant by swimming through the use of flagella (43). The mechanisms of invasion are unknown; however, production of pectinolytic enzymes $(37,39)$ and twitching motility $(20,24)$ seem to be important factors during this process. Twitching motility is a slow migration of bacteria over a solid surface and is mediated by type IV pili (Tfp) (26). Tfp biogenesis requires at least 35 genes in the model organism Pseudomonas aeruginosa (26). The operon pilMNOPQ has been identified in genomes of $R$. solanacearum that have been sequenced $(13,35,36)$. The function of one of those proteins, PilQ, is to form gated pores in the outer membrane through which the pilus is thought to extrude (26), and the protein is an integral part of the apparatus. PilQ mutants defective in the 
production of pili did not show twitching motility and caused reduced symptoms and slower progress of disease symptoms (24); thus, the expression of the pilQ gene constitutes a good marker to evaluate twitching activity.

Little is known on how environmental factors affect the process of colonization, especially temperature. Currently it is known that $\mathrm{R} 3 \mathrm{~B} 2$ strains are pathogenic at temperatures below $25^{\circ} \mathrm{C}$ on potato and other solanaceous hosts $(6,28)$; however, there is little knowledge of virulence at low temperatures for strains of $R$. solanacearum that are already present in the United States and belong to other groups.

In this work, we compared aggressiveness of 11 strains of $R$. solanacearum on tomato and potato at 30 and $18^{\circ} \mathrm{C}$. Those two temperatures are typical at lowland and highland environments, respectively, present in tropical regions, and possibly present in temperate regions of the United States during planting season of solanaceous crops. Virulence, growth, and twitching activity of four selected strains with differential cool virulence behavior were characterized in order to identify possible major factors affecting their virulence at low temperatures. In this work we identified strains established in Florida from the R1B1 Phylotype $(\mathrm{Ph})$ IIB-Sequevar 4 that are virulent at $18^{\circ} \mathrm{C}$ and we provide evidence that twitching is attenuated for the nonpathogenic strains, while it is not for the cool virulent ones when in contact with tomato roots at $18^{\circ} \mathrm{C}$.

\section{MATERIALS AND METHODS}

Bacterial strains and host plants. Eleven $R$. solanacearum strains were selected for this study (Table 1). The list includes six strains endemic to Florida obtained from the culture collection of the Department of Plant Pathology at the University of Florida, with the remaining ones of different origins not endemic to Florida. $R$. solanacearum strains were routinely cultured on either casamino acids-peptone-glucose (CPG) liquid medium (glucose at $5.0 \mathrm{~g} / \mathrm{liter}$, casamino acids at $1.0 \mathrm{~g} / \mathrm{liter}$, and peptone at $10.0 \mathrm{~g} /$ liter) for $24 \mathrm{~h}$ or triphenyl tetrazolium chloride (TZC) solid medium (CPG plus 1\% 2,3,5-triphenyl tetrazolium chloride at $5 \mathrm{ml} /$ liter and Bacto Agar at $16.0 \mathrm{~g} /$ liter) for $48 \mathrm{~h}$.

Two species members of the family Solanaceous were used for this work: tomato (Solanum lycopersicon 'Walter') and potato (Solanum tuberosum 'Red Pontiac'). Seed potatoes were provided by Maine Farmer's Exchange, Presque Isle, ME. Tomato plants were established from seeds in our collection. For pathogenicity and virulence tests, plants were grown in $9 \mathrm{~cm}$ pots containing Vergro Mix A (60\% Canadian peat, 20\% vermiculite, and $20 \%$ perlite; Verlite Company Tampa, FL) in a greenhouse with temperatures maintained at 18 or $32^{\circ} \mathrm{C}$ and maximum lighting at $266 \mu \mathrm{mol} \cdot \mathrm{m}^{-2} \cdot \mathrm{s}^{-1}$.

In vitro tomato seedlings and inoculation with $R$. solanacearum. Tomato cultivar Walter seeds were germinated on water agar plates (Bacto Agar at $16.0 \mathrm{~g} /$ liter, $\mathrm{pH}$ 7.0). Five seedlings (approximately 2 to $4 \mathrm{~cm}$ long) were transferred to a test tube (Pyrex $25 \times 150 \mathrm{~mm}$ ) containing $20 \mathrm{ml}$ of MSMOS liquid medium (Murashige-Skoog plus organics, Sigma M6899); supplemented with sucrose at $30 \mathrm{~g} / \mathrm{liter}, \mathrm{pH}$ 5.8. A sterile plastic mesh was used to separate the seedlings from the liquid medium. The plants were grown in vitro about 10 weeks at approximately $24^{\circ} \mathrm{C}$ and $88 \mu \mathrm{mol} \cdot \mathrm{m}^{-2} \cdot \mathrm{s}^{-1}$ with a regime of $12 \mathrm{~h}$ light and $12 \mathrm{~h}$ dark until roots were well established and filled most of the liquid medium. To establish bacteria-plant root co-cultures in vitro, $R$. solanacearum populations were grown in CPG liquid medium to an exponential phase $\left(\mathrm{OD}_{600}=0.8\right)$. Each test tube containing five tomato plantlets was inoculated with $200 \mu \mathrm{l}$ of the cell suspension. Co-cultures were incubated for 5 days at $18^{\circ} \mathrm{C}$ and for 2 days at $30^{\circ} \mathrm{C}$, both on a rotary shaker $(150 \mathrm{rpm})$.

Pathogenicity tests. Bacterial colonies of individual strains of $R$. solanacearum (Table 1) were grown at $28^{\circ} \mathrm{C}$ for $24 \mathrm{~h}$ in $\mathrm{CPG}$ liquid cultures. In order to prepare the inoculum, bacterial suspensions were washed with deionized sterile water and adjusted to $\mathrm{OD}_{600}=0.1\left(1 \times 10^{8} \mathrm{CFU} / \mathrm{ml}\right)$ using a spectrophotometer (Nanodrop 2000C, Thermo Scientific). The dilutions were prepared in saline solution $(\mathrm{NaCl}$ at $8.5 \mathrm{~g} /$ liter). Individual plants were inoculated by pouring $50 \mathrm{ml}$ of bacterial suspension onto the soil surface in the pot (approximate soil weight of $83 \mathrm{~g} / \mathrm{pot}$ ). Potato plants were inoculated with $50 \mathrm{ml}$ of a $1 \times 10^{8} \mathrm{CFU} / \mathrm{ml}$ $\left(6 \times 10^{7} \mathrm{CFU} / \mathrm{g}\right.$ of soil $)$, while tomato plants were inoculated with $50 \mathrm{ml}$ of a dilution of $1 \times 10^{7} \mathrm{CFU} / \mathrm{ml}\left(6 \times 10^{6} \mathrm{CFU} / \mathrm{g}\right.$ of soil $)$. Plants were placed in environmental chambers set at a constant temperature $\left(18\right.$ or $30^{\circ} \mathrm{C}$ ) and on a $12 \mathrm{~h}$ day/night cycle at a light intensity of $310 \mu \mathrm{mol} \cdot \mathrm{m} \cdot \mathrm{m}^{-2} \cdot \mathrm{s}^{-1}$. Plant wilt was recorded at $24 \mathrm{~h}$ intervals. Number of plants completely wilted per treatment was recorded daily. At the end of each experiment the percentage of wilted plants per treatment was used as measured parameter. Ten plants were inoculated per treatment, with temperature and strain as parameters. Experiments were repeated three times and results were combined.

Isolations were made from every plant in the experiment by cutting an approximate $20-\mathrm{mm}$ cross section of the plant stem above the cotyledon leaves. Stem sections were surface sterilized $(0.3 \% \mathrm{NaOCl})$ for $10 \mathrm{~min}$, rinsed in sterile distilled water, and ground in $300 \mu \mathrm{l}$ of sterile distilled water. Nondiluted extracts from the stem isolation were plated onto TZC plates by streaking. A set of plants was inoculated with saline solution as negative control.

Virulence assays and in stem multiplication. Inoculum was prepared as described in the previous section. Individual plants were injected in the stem with $1 \mu \mathrm{l}$ of a $1 \times 10^{6} \mathrm{CFU} / \mathrm{ml}(1,000$ cells) suspension at the base of the cotyledons and incubated in environmental chambers as described in the previous section. Disease severity index was recorded daily using a grading system as follows: $1=$ one or two leaves wilted, $2=$ three or four leaves wilted, 3 = five leaves wilted, and $4=$ plant completely wilted.

Isolations were made from every plant in the experiment by cutting an approximate $20-\mathrm{mm}$ cross section of the plant stem above the cotyledon leaves as described previously. In order to assess the population present in stems, $100 \mu \mathrm{l}$ of $10^{-4}$ dilutions of the stem extract was plated by spreading. An estimated order of

TABLE 1. Ralstonia solanacearum strains used in this study

\begin{tabular}{|c|c|c|c|c|c|}
\hline Strain ID & Race/biovar & Phylotype/sequevar & Source & Host geographic origin & Reference \\
\hline UW551 & R3B2 & IIB-1 & Geranium & Kenya & $(42)$ \\
\hline P666 (LMG17140) & R3B2 & IIB-1 & Potato & Sweden & (31) \\
\hline P446 & R1B1 & IIB-4 & Pothos & Florida & (30) \\
\hline P487 & R1B1 & IIB-4 & Pothos & Florida & (30) \\
\hline P506 & R1B1 & IIB-4 & Pothos & Florida & $(30)$ \\
\hline P673 & R1B1 & IIB-4 & Pothos & Florida & $(30)$ \\
\hline P618 (99.1119/1) & R1B1 & IIB-4 & Anthurium & Martinique & (30) \\
\hline P597 & R1B1 & IIA-38 & Tomato & Florida & This work \\
\hline P550 & R1B1 & IIA-7 & Potato & Florida & $(30)$ \\
\hline GMI 1000 & R1B3 & I-18 & Tomato & Guyana & (8) \\
\hline MT1 & R1B3 & $\mathrm{I}-12$ & Tomato & Martinique & (12) \\
\hline
\end{tabular}


magnitude colony concentration in the stem was recorded. Stem samples were taken as soon as the plant was completely wilted. Asymptomatic plants or plants not completely wilted were maintained in the environmental chambers for 30 or 40 days at 30 or $18^{\circ} \mathrm{C}$, respectively, before taking the stem samples. A set of plants was inoculated with saline solution as negative control. Results of two independent experiments with a total of 30 plants per treatment were combined and averaged.

Statistical analysis. Data for pathogenicity tests were analyzed for statistical significance using mean values to perform analysis of variance and $t$ tests with the Fisher's least significant difference (LSD) criterion at $P<0.05$ to compare strains for each host. SigmaPlot for Windows version 11.0 (Systat Software, Inc.) was used to perform statistical calculations.

$\boldsymbol{R}$. solanacearum growth curves. Bacteria were grown on nutrient agar plus 5\% sucrose (NAS) solid medium for $24 \mathrm{~h}$ at $28^{\circ} \mathrm{C}$ prior to inoculation to liquid culture. Two bacterial media were used for this experiment: (i) nutrient broth (NB) (Bacto Nutrient Broth, Difco Laboratories, Detroit, MI, plus 5\% sucrose) or (ii) Clough's minimal medium (MM) (7). Prior to inoculation, bacterial suspensions were freshly prepared in the corresponding medium from individual colonies and adjusted with a spectrophotometer to a concentration of $\mathrm{OD}_{600}=0.1\left(10^{8} \mathrm{CFU} / \mathrm{ml}\right)$. A $1: 10$ volume of the suspension $\left(10^{7} \mathrm{CFU} / \mathrm{ml}\right)$ was added to $40 \mathrm{ml}$ of either medium in Erlenmeyer flasks and incubated on a shaker at $200 \mathrm{rpm}$. Bacterial density was measured at hourly intervals using the spectrophotometer.

Twitching motility. To observe comparative twitching behavior on growing colonies, P673, P597, GMI1000, and UW551 suspensions were diluted and plated on rich solid medium (NAS) or on minimal solid medium (Clough's MM plus Bacto Agar at $16 \mathrm{~g} /$ liter) (7) and immediately placed at 30 and $18^{\circ} \mathrm{C}$ with high humidity for incubation. Dilutions were made such as to obtain an observable number of CFU per plate. Plates were observed under the microscope (Leica Wild M10) from 15 to $140 \mathrm{~h}$ postinoculation (hpi). Pictures were taken at $80 \times$ magnification and modified by cropping and adjustment of color, brightness, and contrast only to improve visibility against a gray background. In order to quantify the amount of twitching for comparative purposes, the rank classification of Liu et al. (24) was used to assess the degree of twitching activity by the colony appearance (twt: ++ for high activity; twt: + for moderate activity; and twt: - for no twitching activity). Suspensions for observation of twitching motility were prepared from colonies from freezer stocks grown on NAS plates for $24 \mathrm{~h}$ at $28^{\circ} \mathrm{C}$.

Total RNA extraction. Cell samples from bacterial co-cultures with tomato roots were extracted as follows: the suspension was filtered with a $20 \mu \mathrm{m}$ filter (Steriflip, Millipore) to eliminate all plant debris. Filtrate was centrifuged at $8,000 \times g$ and pellet was collected and suspended in RNA Bacteria Protect Reagent (Qiagen Cat. 76506) following the manufacturer's instructions. Prepared samples were stored at $-70^{\circ} \mathrm{C}$ for further processing. Total RNA was extracted from the stored cell samples using the Qiagen RNeasy extraction kit (Cat. 27104) and DNAse digested during the column purification using the RNase Free-DNase Kit (Qiagen, Cat. 79254) following manufacturer's instructions. Quantity of extracted RNA was measured using the Nanodrop 2000C spectrophotometer. Quality was assessed on denaturing electrophoresis gels.

Preparation of RNA for real-time polymerase chain reaction and primer design for relative quantification. Primers were designed for a 188-bp fragment of the 16sRNA sequence (16sRNA_forward: TGCACGAAAGCGTGGGGAGC, 16sRNA_reverse: CATCCACCGCTTGTGCGGGT), and a 200-bp fragment of pilQ sequence (pilQ_forward: GTGGACGTCAACAAGG ACAG, pilQ_reverse: CTCTTGAACAGGTTGCCCAG). Total RNA of each sample was diluted to obtain concentrations of $2 \mathrm{pg} / \mathrm{ml}$ to $2 \mathrm{ng} / \mathrm{ml}$ measured using the spectrophotometer. Rela- tive quantification real-time PCR (qRT-PCR) was performed using the Roche Lightcycler 480 with the Express One-Step SYBR GreenER kit (Invitrogen, Cat No. 11780). Melting curves of the samples were assessed to evaluate contamination, and standard curves were used to calculate the amplification efficiency. The ratio of pilQ/16sRNA amplification at $18^{\circ} \mathrm{C}$ was normalized against the ratio of each strain at $30^{\circ} \mathrm{C}$ for the relative quantification analysis. The program used was $95^{\circ} \mathrm{C} \times 2 \mathrm{~min}$ initial incubation, followed by up to 60 cycles of amplification $\left(95^{\circ} \mathrm{C} \times\right.$ $\left.15 \mathrm{~s}, 60^{\circ} \mathrm{C} \times 1 \mathrm{~min}\right)$, the melting curve program, and a final extension at $40^{\circ} \mathrm{C} \times 30 \mathrm{~s}$.

\section{RESULTS}

R. solanacearum strains endemic to Florida are pathogenic on tomato at low temperatures. For this work we use the term pathogenicity as the ability of a pathogen to cause disease to a host (1). The term virulence is used to describe the degree of damage that a pathogen can cause to a host, measured by the symptoms (2), while the term aggressiveness is defined as the percentage of wilted plants in a pathogenicity test. Finally, we define the term "cool virulence" as virulence at low temperatures.

The eleven $R$. solanacearum strains tested were pathogenic at $30^{\circ} \mathrm{C}$ on tomato (Fig. 1A). P550 from group R1B1 IIA-Sequevar 7 and MT1 from group R1B3 were the least aggressive strains. Both strains wilted less than $60 \%$ of test plants, significantly fewer than the other strains compared with a Fisher's LSD test. All infected tomato plants wilted by 10 days postinoculation (dpi) except the ones inoculated with UW551 which reached $100 \%$ wilted plants by 15 dpi. Plants inoculated with phosphate buffer as a control did not show any symptoms.

At $18^{\circ} \mathrm{C}$ only $\mathrm{P} 597$ from group R1B1 IIA-Sequevar 38 was nonpathogenic on tomato (Fig. 1A). Aggressiveness was variable for the rest of the strains. The least aggressive were GMI1000 and MT1 both from R1B3 I-Sequevar 18 with a mean percentage of wilted plants of $3 \%$. Both strains statistically grouped with P597, in consequence they were considered nonpathogenic at $18^{\circ} \mathrm{C}$. In contrast, four strains from group R1B1 IIB-Sequevar 4 (P673, P446, P487, and P618), and UW551 from group R3B2 IIBSequevar 1 were significantly more aggressive than the other strains tested. The strains from Sequevar 4 were all isolated from pothos (Epipremnum aureum) or Anthurium sp. plants. As an exception, P506, a strain from the same Sequevar 4 and also isolated from pothos plants, was significantly less aggressive than strains P673, P446, P487, and P618. At $18^{\circ} \mathrm{C}$ the tomato plants infected with strains that were aggressive started wilting after 20 and $25 \mathrm{dpi}$, and achieved their final disease percentage between 40 and 50 dpi.

On potato plants all strains were pathogenic at $30^{\circ} \mathrm{C}$ (Fig. 1B). For this host, most of the strains were also aggressive as evidenced by the high percentage of wilted plants. GMI1000 and P446 were the only strains significantly less aggressive with mean percentages of wilted plants of 46 and $33 \%$, respectively. The first wilted plants were observed between 3 to 8 dpi and plants continued wilting progressively reaching the final percentage between 30 to 40 dpi.

By contrast, at $18^{\circ} \mathrm{C}$ GMI1000, MT1, P506, and P597 were nonpathogenic (Fig. 1B) on potato. Only strains UW551 and LMG1714 (R3B2 IIB-Sequevar 1) were significantly more aggressive than the rest. In general, potato plants were less susceptible to the $R$. solanacearum infection than tomato plants at the same concentration of inoculum. Pathogenic strains started wilting potato plants between 15 to $20 \mathrm{dpi}$, and continued wilting progressively until near the end of the experiment after $40 \mathrm{dpi}$.

When stem extracts from wilted plants were plated on TZC plates, all without exception had high viable $R$. solanacearum populations, while nonsymptomatic hosts, including control plants, revealed no viable populations on the plates. 
$R$. solanacearum strains naturally nonpathogenic at low temperatures are able to survive and produce limited disease symptoms when inoculated directly in the stem of host plants at $18^{\circ} \mathrm{C}$. In order to further evaluate differences between pathogenic and nonpathogenic strains at $18^{\circ} \mathrm{C}$, four $R$. solanacearum strains with differential pathogenic behavior at low temperature were selected and their virulence tested on tomato. The strains are P673 and UW551, which were aggressive pathogens at $18^{\circ} \mathrm{C}$ when soil inoculated, and P597 and GMI1000, which were nonpathogenic. This time the strains were directly inoculated in the stems in order to evaluate their behavior when the host barrier at the rhizosphere was eliminated. As expected, the four strains tested were virulent on tomato plants at $30^{\circ} \mathrm{C}$ (Fig. 2A), wilting all plants completely by $10 \mathrm{dpi}$. The progress of the disease was very rapid and the severity of the infection caused the stems to ooze at the site of inoculation or closer to the top of the plant. As noted in Figure 2A, the disease index for UW551 progressed slower than the index for the other strains, and the ooze appeared in only $10 \%$ of wilted plants. No symptoms were observed for the negative control plants. In general, the wilting was more rapid and

\section{A Tomato 'Walter'}

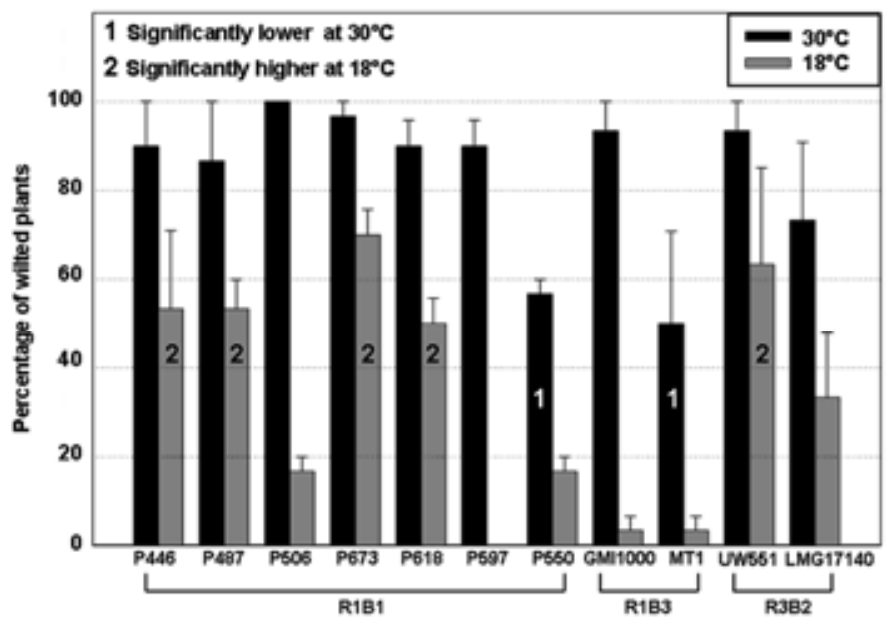

B Potato 'Red Pontiac'

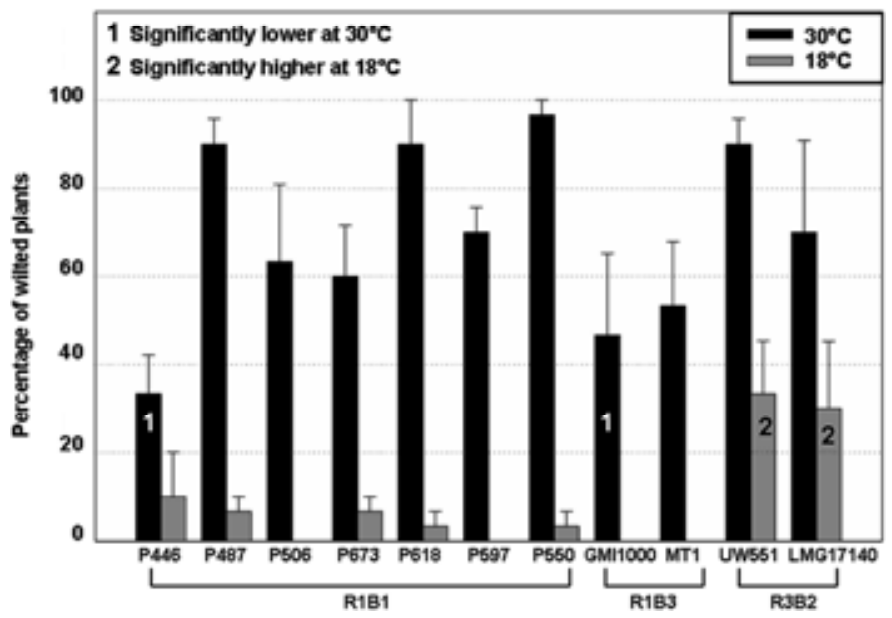

Fig. 1. Percentage of wilted plants for 11 Ralstonia solanacearum strains soil inoculated at 30 and $18^{\circ} \mathrm{C}$. Ten plants per treatment were inoculated by applying $50 \mathrm{ml}$ of bacterial suspension in the soil. Wilting was observed and recorded daily on A, tomato 'Walter' plants and B, potato 'Red Pontiac' plants. Each experiment was repeated three times and results were combined. Histograms show the average of final percentage of wilted plants. Error bars indicate standard error. Numbers indicated in the histogram bars correspond to strains with statistically significant difference as determined by Fisher's least significant difference tests at $P<0.05$. symptoms more severe for this experiment than for our previous pathogenicity tests at $30^{\circ} \mathrm{C}$.

At $18^{\circ} \mathrm{C}$, the difference between the cool virulent and nonpathogenic strains was significant (Fig. 2B). P673 and UW551 were highly virulent since they wilted all plants completely by 22 dpi. Although severity index for all the plants infected with P673 was high, only $20 \%$ of the plants had visible ooze on the stems in contrast with $100 \%$ affected plants at $30^{\circ} \mathrm{C}$. When inoculated directly in the stem, GMI1000 was able to cause disease in all the plants, in contrast to the results of the soil inoculation test at $18^{\circ} \mathrm{C}$. The severity of the disease was consistently low (Fig. 1B) since no plant had more than two or three wilted leaves during the experiment. P597 was able to cause disease in most of the inoculated plants with varying degree of response from the plants: approximately $36 \%$ of the tested plants were completely wilted (severity index 4), while most of remainder plants had no visible symptoms at the end of the experiment. This variation explains the magnitude of the error bars for P597 at $18^{\circ} \mathrm{C}$ (Fig. 2B). The negative controls had no viable populations in the stems.

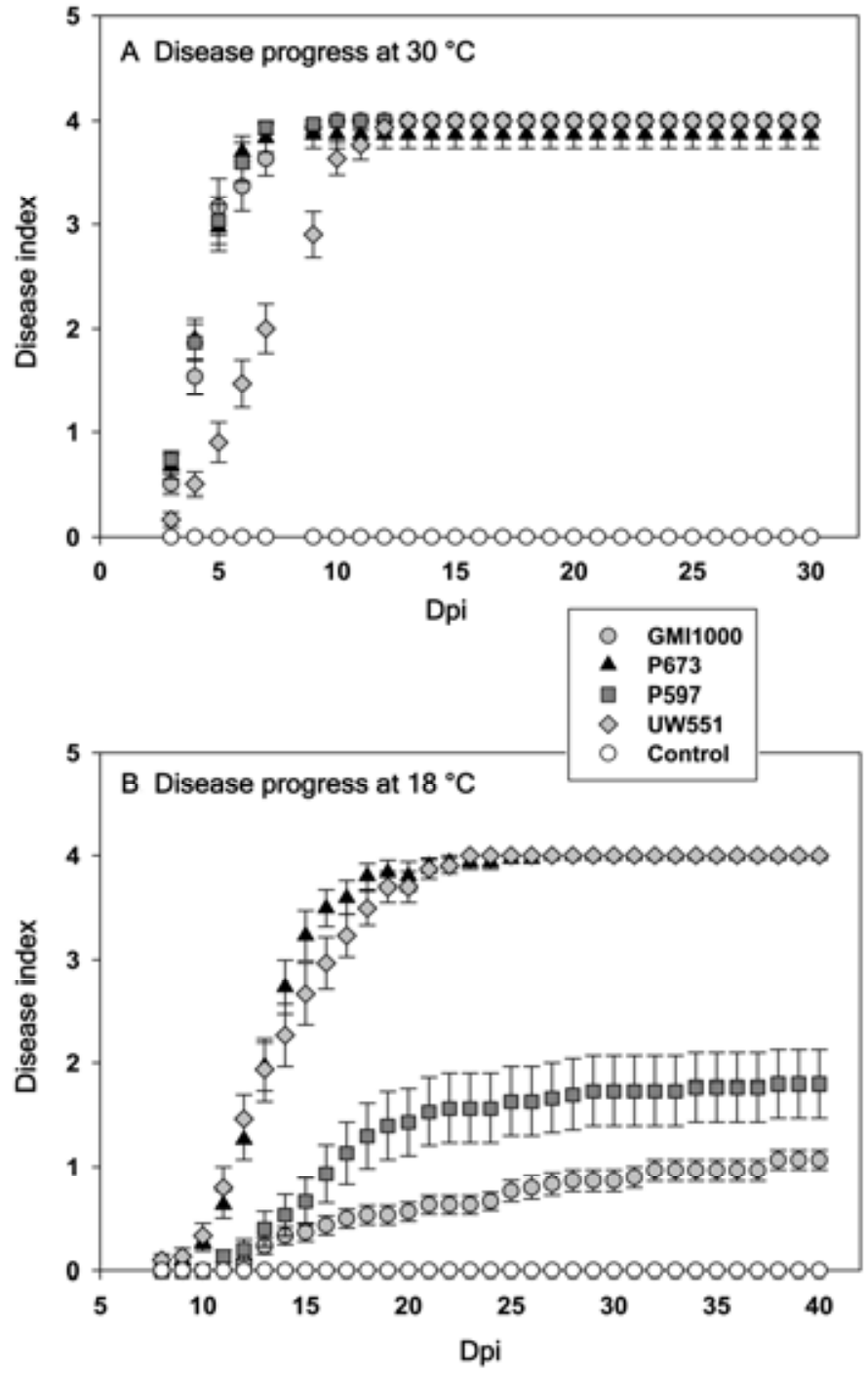

Fig. 2. Disease progress of tomato plants 'Walter' stems inoculated at $\mathbf{A}, 30^{\circ} \mathrm{C}$ and $\mathbf{B}, 18^{\circ} \mathrm{C}$. Tomato plants were inoculated by injecting approximately 1,000 $\mathrm{CFU}$ of bacteria directly in the stem. Wilt progress was observed and recorded daily as an index (0: no symptoms, 1: low, 2: moderate, 3: high, and 4: complete wilt). Fifteen plants per experiment, per treatment for two experiments, were combined and averaged. Vertical axis reports average disease index with standard error bars. Horizontal axis represents the days postinoculation. 
Multiplication and movement in stems is limited at low temperatures in $R$. solanacearum strains that are naturally nonpathogenic at low temperatures. Although plants inoculated with GMI1000 and incubated at $18^{\circ} \mathrm{C}$ did not show severe wilting symptoms (Fig. 2B), high viable populations of $R$. solanacearum were recovered from inside the stems $\left(>10^{8} \mathrm{CFU} / \mathrm{ml}\right)$. The internal stem tissue was necrotic (Fig. 3A) with visible signs of damage for at least $4 \mathrm{~cm}$ around the site of inoculation. These results suggest that GMI1000 is capable of surviving and reproducing in the stem of its host, and even capable of limited movement through the vascular system at $18^{\circ} \mathrm{C}$, similarly to latent infections in tolerant or resistant plants $(41,42)$. As for the case of latent infections, bacterial populations in the stem were not correlated with disease severity. The severe necrosis observed in the stem probably is associated with the method of inoculation and the ability of the strain to reproduce in the stem.
In contrast, P597 survival in tomato stems seemed to be correlated with its ability to cause symptoms in the host, in other words high viable populations were associated with more severe symptoms $\left(>10^{8} \mathrm{CFU} / \mathrm{ml}\right)$, while asymptomatic plants did not have viable populations in the stem. Similarly, the signs of damage in the stem were associated with the severity of the disease: asymptomatic plants had completely healthy looking stems similar to the stems of control plants (Fig. 3B), stems of plants with disease index 1 or 2 had slightly necrotic stems (Fig. 3C), and stems of completely wilted plants were completely damaged. Unlike the case of GMI1000 inoculations, plants with partial wilt symptoms did not have visible damage of the stem further than $4 \mathrm{~cm}$ up or down the point of inoculation. P597 was also capable of surviving and reproducing in the stem of its host at low temperature, however strain GMI1000 consistently survived better in planta than P597 and was capable of a higher range of
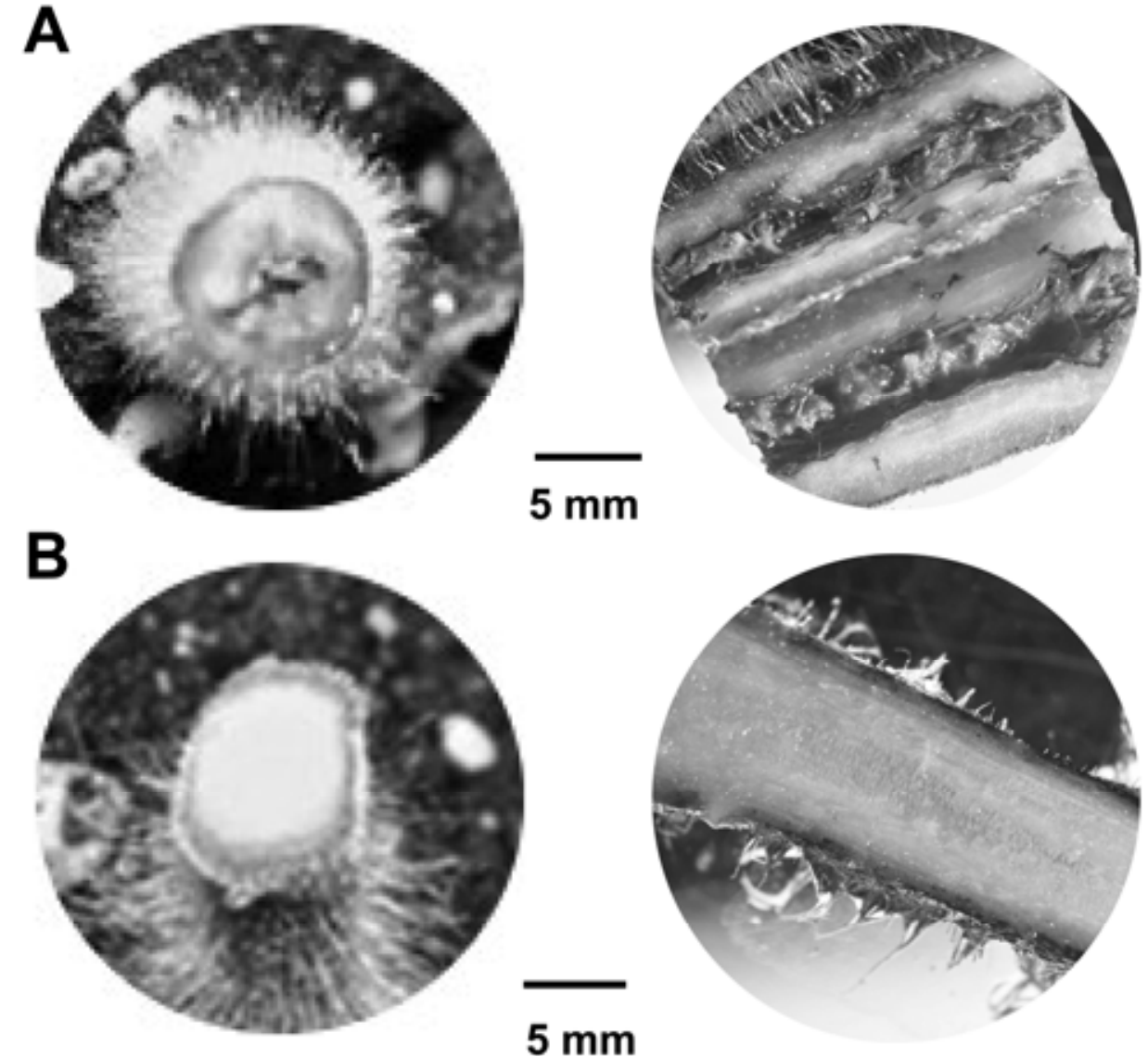

$5 \mathrm{~mm}$
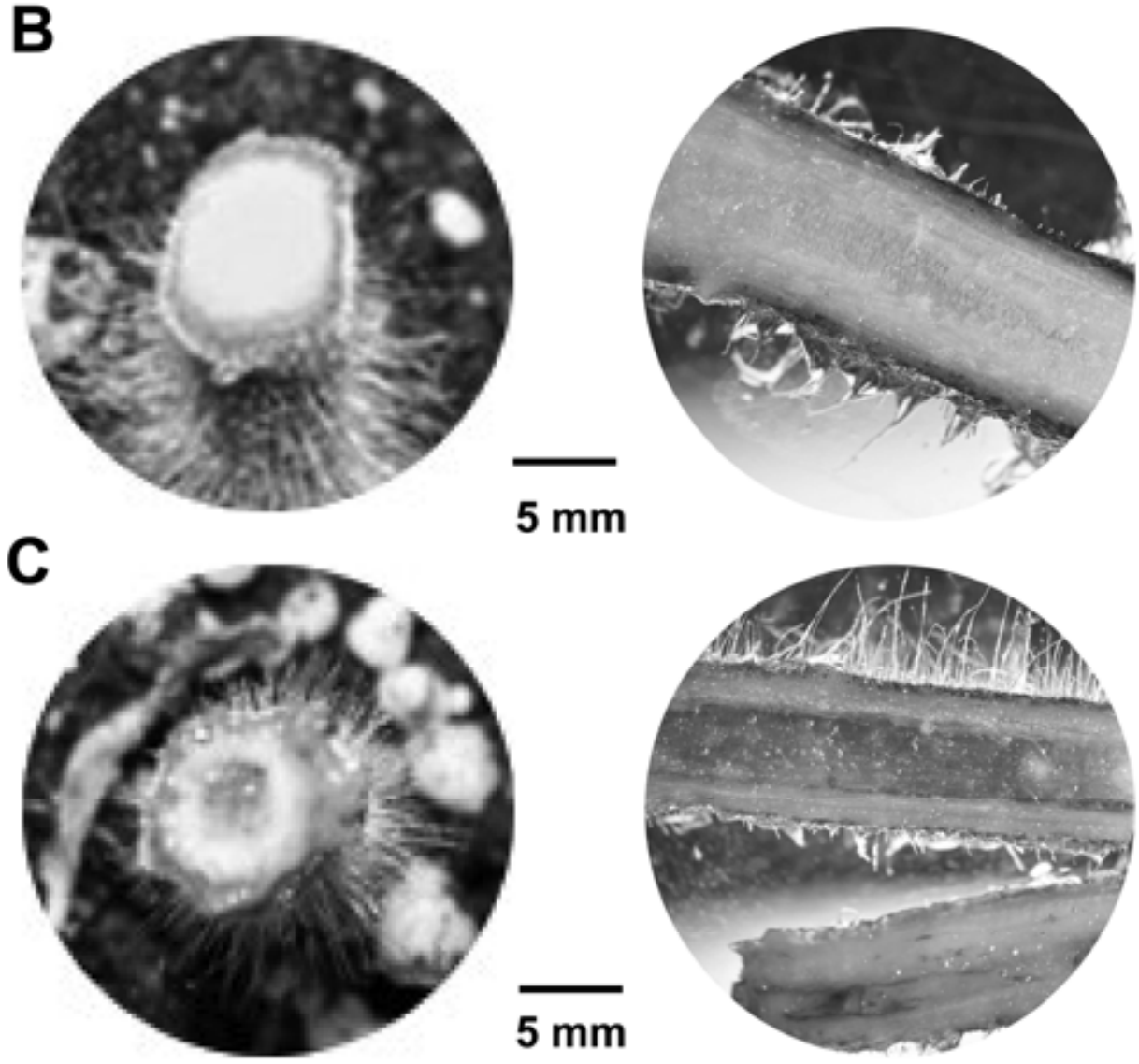

\section{$5 \mathrm{~mm}$}

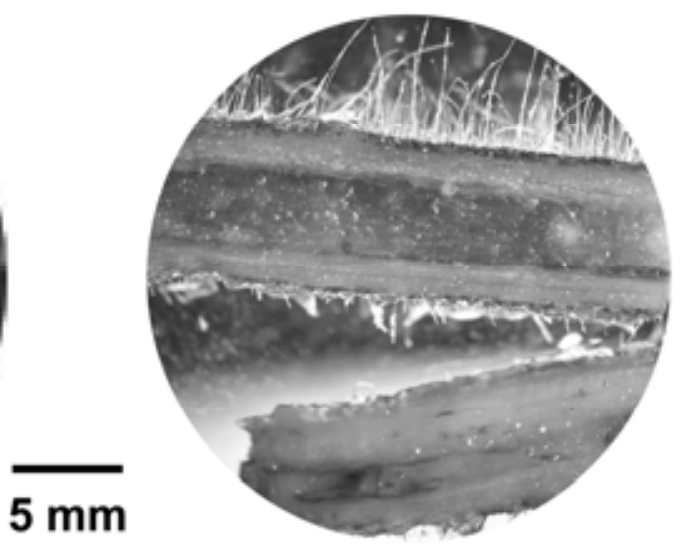

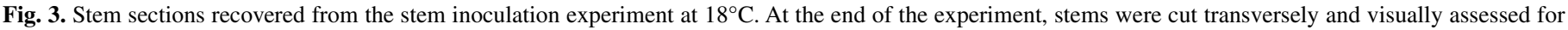

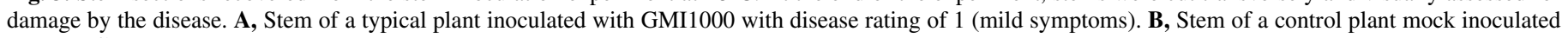
(buffer). C, Stem of a typical plant inoculated with P597 with disease rating of 2 or 3 (moderate symptoms). 
movement through the stem at $18^{\circ} \mathrm{C}$ without causing severe disease symptoms. The plants inoculated with buffer had no viable $R$. solanacearum populations and no damage of the stem (Fig. 3B).

Comparative in vitro growth of $R$. solanacearum strains at two temperatures. Bacterial growth at 30 and $18^{\circ} \mathrm{C}$ was recorded for P673, P597, GMI1000, and UW551 strains in either NB or MM for comparison purposes. All strains grown in $\mathrm{NB}$ at $30^{\circ} \mathrm{C}$ (Fig. 4A) reached stationary phase between 30 to 40 hpi. At $18^{\circ} \mathrm{C}$ (Fig. 4B) the strains reached stationary phase with a 20 to $30 \mathrm{~h}$ delay compared with growth at $30^{\circ} \mathrm{C}$. The bacterial population at stationary phase was similar for all strains at both temperatures $\left(\approx 10^{10} \mathrm{CFU} / \mathrm{ml}\right)$; however, P673 grew slightly better than the rest of the strains while UW551 grew slightly less at both temperatures. The same tendency was observed in all experiments. There was no observable differential effect of temperature on the bacterial density at stationary phase at $18^{\circ} \mathrm{C}$ compared with the density at $30^{\circ} \mathrm{C}$ for the nonpathogenic strains compared with the cool virulent ones.

Growth of all strains in MM (Fig. 4C and D) was reduced at both temperatures in comparison with growth in NB (Fig. 4A and B). GMI1000 and P597 grew to a higher density than the other two strains at $30^{\circ} \mathrm{C}$ (Fig. 4C), while GMI1000 grew to a higher density $\left(3 \times 10^{9} \mathrm{CFU} / \mathrm{ml}\right)$ than P597 $\left(2 \times 10^{8} \mathrm{CFU} / \mathrm{ml}\right)$ at $18^{\circ} \mathrm{C}$.

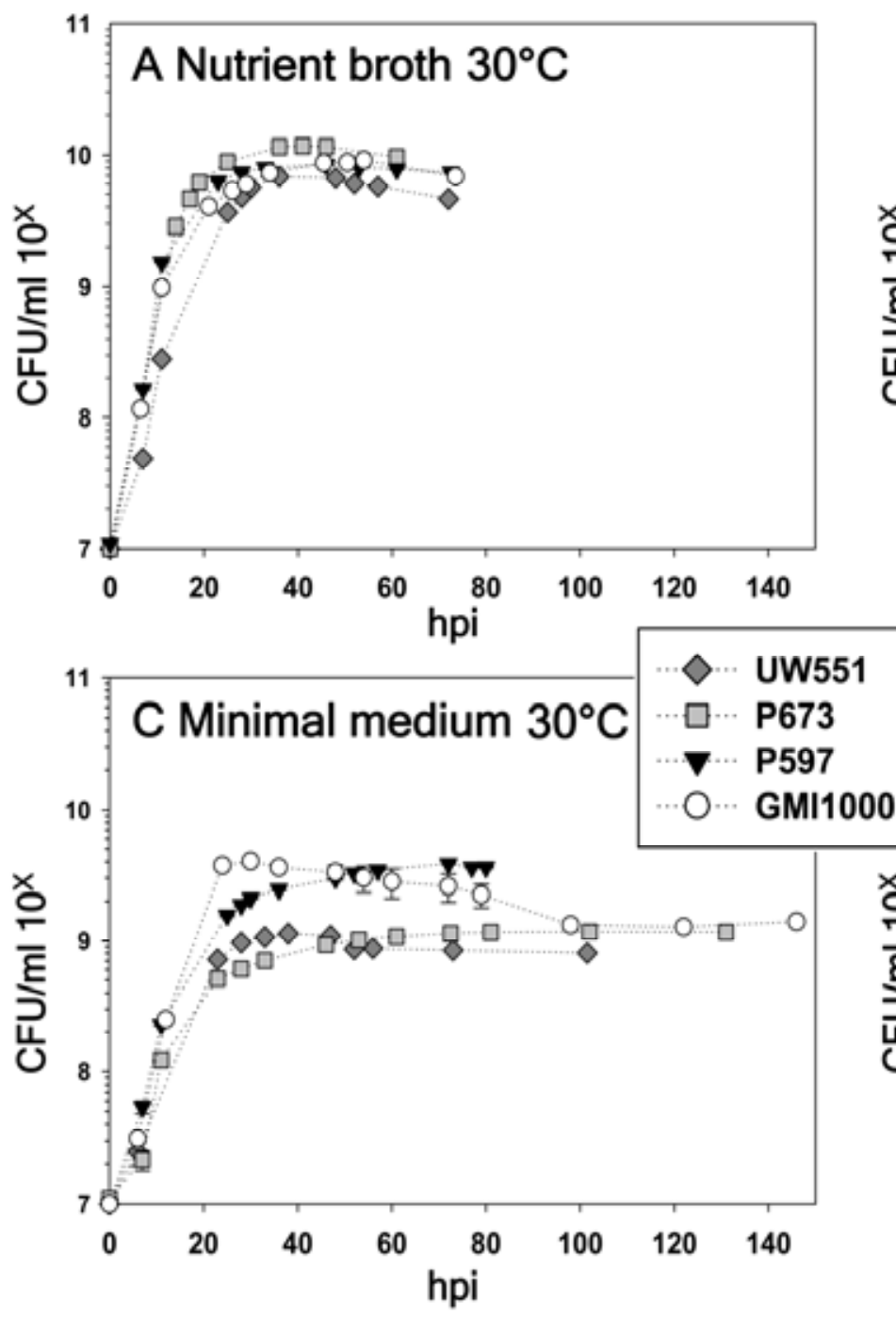

Characterization of twitching behavior of $R$. solanacearum strains at two temperatures. Colonies of all tested strains growing on solid NAS at $30^{\circ} \mathrm{C}$ showed a high twitching activity between 18 and 24 hpi when the colonies reached a high density and twitching rafts were no longer observable. On solid $\mathrm{MM}$ at $30^{\circ} \mathrm{C}$ colonies were not visible at the highest magnification available $(80 \times)$ before 20 hpi. Twitching activity was attenuated and lasted longer (up to $60 \mathrm{hpi}$ ) when compared with activity on NAS (images not shown). Colony growth was limited, as evidenced by smaller size of MM colonies compared with NAS. Results were similar to colony phenotype and development reported previously for $R$. solanacearum strains growing at $28^{\circ} \mathrm{C}$ (24).

Colony growth at $18^{\circ} \mathrm{C}$ on NAS was delayed compared with growth at $30^{\circ} \mathrm{C}$. Colonies were first observable under the microscope $(80 \times)$ by 48 hpi (Supplemental Figure 1). Growth was limited to small colonies which acquired a slimy appearance only after 100 hpi. Colony growth on MM plates at $18^{\circ} \mathrm{C}$ was further limited and delayed compared with growth on NAS at $18^{\circ} \mathrm{C}$. Colonies were first observable under the microscope with the highest magnification available $(80 \times)$ by 66 to 72 hpi (Supplemental Figure 2). At the end of the experiment (140 hpi), all colonies were small with a starlike and dry appearance, suggesting that the colonies never reached the high density necessary to trigger production of exopolysaccharides.

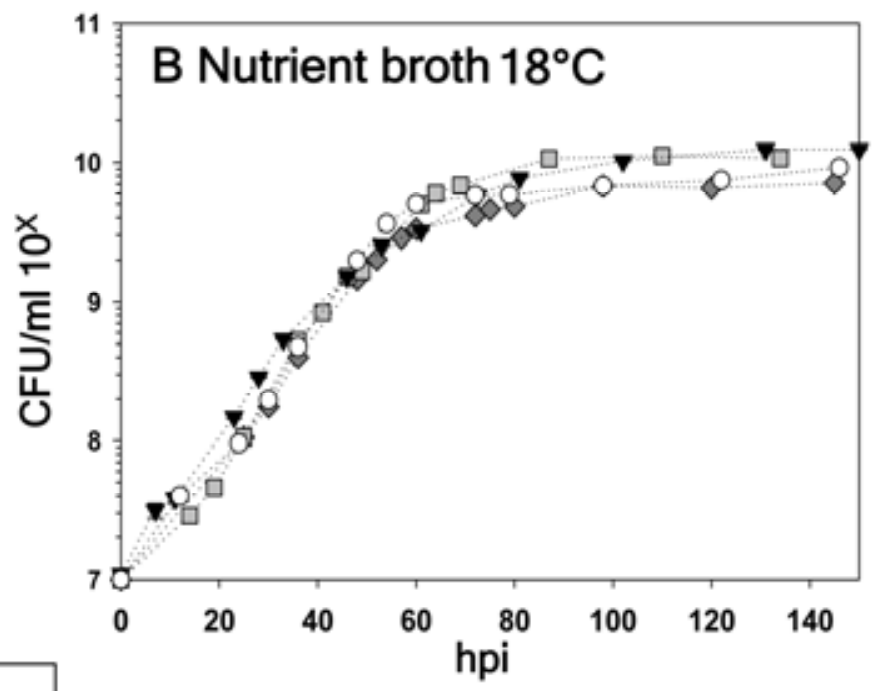

Fig. 4. Growth curves in vitro of Ralstonia solanacearum strains GMI1000, P597, P673, and UW551. Strains were grown in $40 \mathrm{ml}$ of A, nutrient broth at $30^{\circ} \mathrm{C}$, B, nutrient broth at $18^{\circ} \mathrm{C}, \mathbf{C}$, minimal medium at $30^{\circ} \mathrm{C}$, and $\mathbf{D}$, minimal medium at $18^{\circ} \mathrm{C}$. Bacterial density measurements were taken with a spectrophotometer at 4- to 12-h intervals which varied with the growth phase. Three replicates were made for each treatment for at least two independent experiments. Bars represent standard errors. 
In order to visually compare twitching activity at 30 and $18^{\circ} \mathrm{C}$, images of individual colonies actively growing on NAS plates (15 to $19 \mathrm{hpi}$ ) for both temperatures were made (Fig. 5). Cool virulent strains P673 and UW551 grown in vitro maintained high twitching activity at both temperatures, while twitching was attenuated at the lower temperature for nonpathogenic P597 and GMI1000. The same phenomenon was observed on MM plates (images not shown), however results were not as clear because of the attenuating effects of the lack of nutrients in MM.

Our observations indicate that lack of nutrients in the medium had a higher impact on twitching activity than did temperature. Unlike lack of nutrients, change in temperature had a differential impact on twitching activity of the cool virulent strains compared with the nonpathogenic ones.

PilQ is differentially expressed at low temperatures in strains with differential pathogenic behavior at low temperatures. Relative expression of pilQ mRNA versus $16 s R N A$ was measured using quantitative real-time reverse transcriptase PCR analysis (qRT_PCR). The ratio pilQ/16sRNA at $18^{\circ} \mathrm{C}$ was further normalized using the same ratio at $30^{\circ} \mathrm{C}$ as reference value of one for each strain. PilQ expression was downregulated approximately 100 times at $18^{\circ} \mathrm{C}$ compared with $30^{\circ} \mathrm{C}$ in the nonpathogenic strains P597 and GMI1000. In contrast, the normalized ratio between 18 and $30^{\circ} \mathrm{C}$ was less than 10 times for the cool virulent strains P673 and UW551 (Fig. 6). This experiment was repeated for three different biological samples (individual tubes with five seedlings each) of the same experiment, and each biological sample had three replicates. This more sensitive method provided a quantitative measure of the level of twitching activity when the strains were in the rhizosphere of tomato seedlings, while minimally disturbing the root colonization process.

\section{DISCUSSION}

We tested pathogenicity for 11 strains of different evolutionary and geographic origins at $18^{\circ} \mathrm{C}$. We found that strains from the R3B2 PhII-Sequevar 1 group are not unique in their ability to infect tomato and potato at low temperatures. Further comparison of virulence at low temperatures of two cool virulent strains and two nonpathogenic strains revealed that low temperature affects differentially virulence factors at early stages of infection, when the bacterial populations are in contact with host roots. We identified twitching motility as one of the latter factors since decreased twitching activity correlated with loss of virulence at $18^{\circ} \mathrm{C}$.

The 11 strains tested were selected as representatives of different groups present or not in the United States in order to determine if members of groups other than R3B2 are pathogenic to solanaceous hosts at low temperature. All strains were able to infect potato and tomato at $30^{\circ} \mathrm{C}$, while at $18^{\circ} \mathrm{C}$ variation in pathogenicity between strains within specific race-biovar groups was observed. This agrees with previous research revealing a high degree of genetic heterogeneity in $R$. solanacearum $(30,40,46)$. Such differences may reflect evolution of $R$. solanacearum strains in widely different locations and on different host plants (9). Four of the five strains belonging to R1B1 IIB-Sequevar 4 were able to infect tomato and potato at low temperatures. Moreover, these strains were as aggressive as the R3B2 IIB-Sequevar 1 strains on
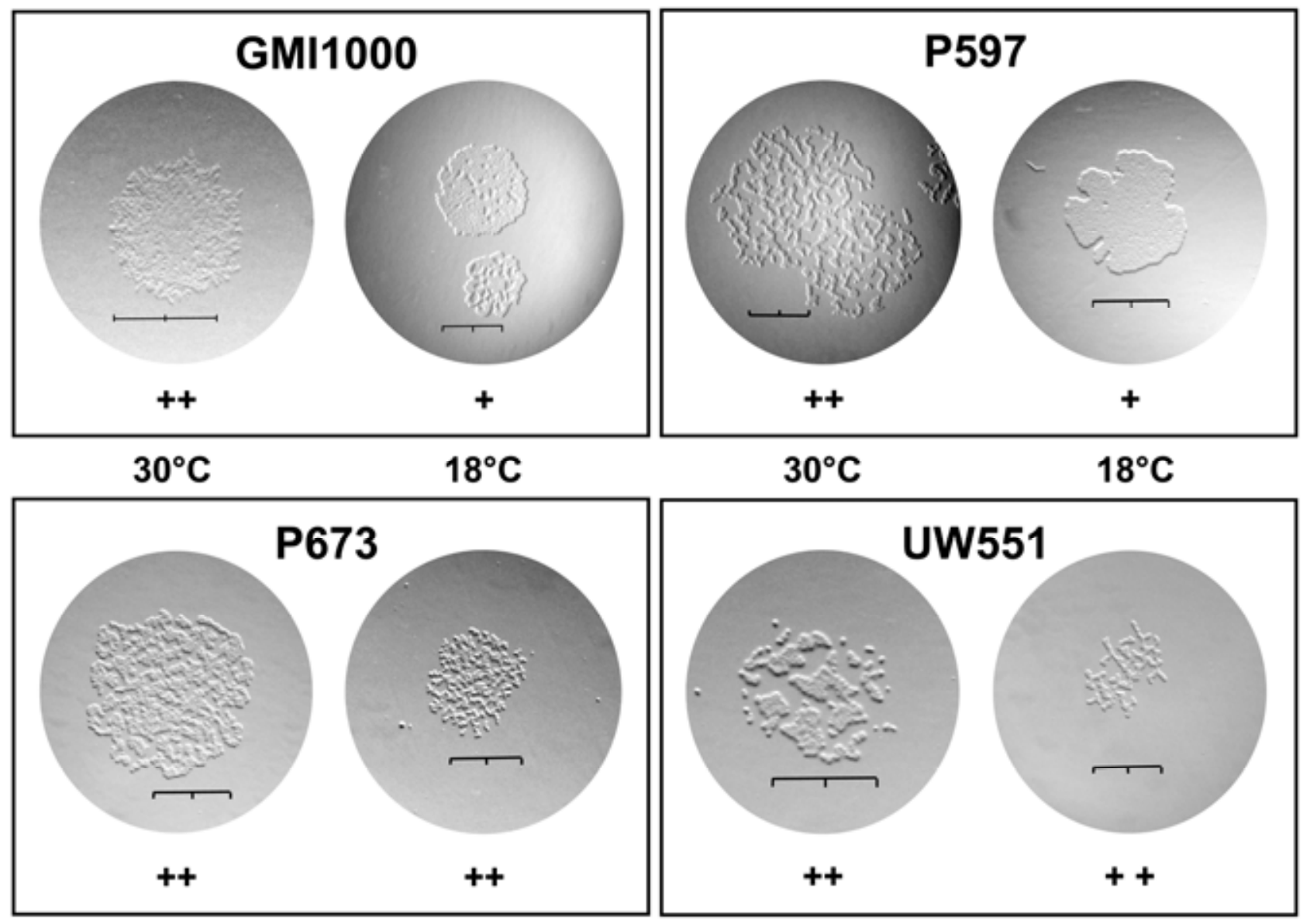

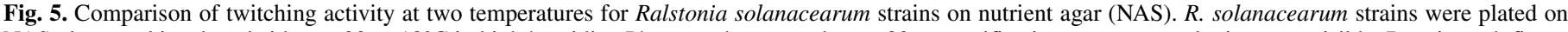

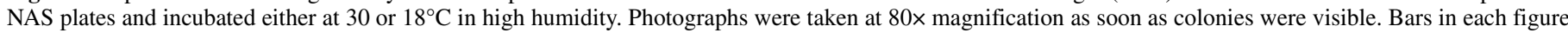

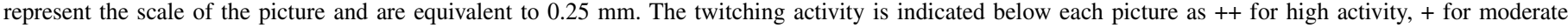

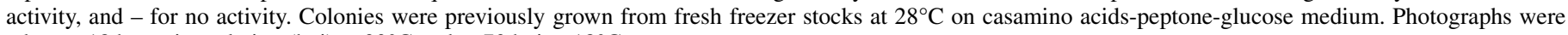
taken at $18 \mathrm{~h}$ postinoculation (hpi) at $30^{\circ} \mathrm{C}$ and at $70 \mathrm{hpi}$ at $18^{\circ} \mathrm{C}$. 
tomato. The strains from Sequevar 4 are known to cause Moko disease on bananas and other Musaceae $(10,11)$. They belong to the same Phylotype IIB group and are closely related to the R3B2-Sequevar 1 strains (33) which are known to cause disease at low temperatures (6). However, their host range and biochemical properties are distinct enough to classify them in different race/biovar groups.

It is known that $R$. solanacearum is a species complex with a very wide and varied host range and it is also highly adaptable. For example, although Sequevar 4 strains have been associated with Moko disease on banana, they are able to infect other plants such as tomato, potato, or geranium (29). The phylogenetic proximity of this sequevar with strains from Sequevar 1 may partially explain this ability of causing disease at low temperatures; however, more strains that belong to Sequevar 4 should be tested on different hosts at $18^{\circ} \mathrm{C}$ to conclude that this ability is associated with a specific phylogenetic group. The fact that strains present in Florida may be pathogenic at low temperatures suggests consequences for potential damage to tomato crops at cooler temperatures. Because this study was performed in controlled environmental conditions and with a specific variety of tomato, it might not reflect all actual field situations. In order to ascertain risk regarding the ability of strains belonging to Sequevar 4 to cause disease at cooler temperatures on tomato and to a limited extent on potato, we need to address the question of potential hazard to various crops based on aggressiveness in the field, possible methods of spread, persistence in the environment, and accessibility to susceptible hosts. In our work, variation in aggressiveness was also observed within a sequevar. P506 (Sequevar 4) was unable to wilt tomato plants at low temperature to the same degree as four other strains of the same sequevar. In this case, variation in aggressiveness could be attributed to variation in specific responses of this strain to temperature or to the individual interaction with the host plant genotype.

Cool virulence of P597, P673, GMI1000, and UW551 was further characterized. The first two strains were selected because they belong to the R1B1 group, are present in the United States, and had contrasting pathogenic behavior at low temperature. The latter two were selected because they also have different pathogenic behavior at low temperatures and have been previously characterized $(8,17)$. More importantly, their genomes have been

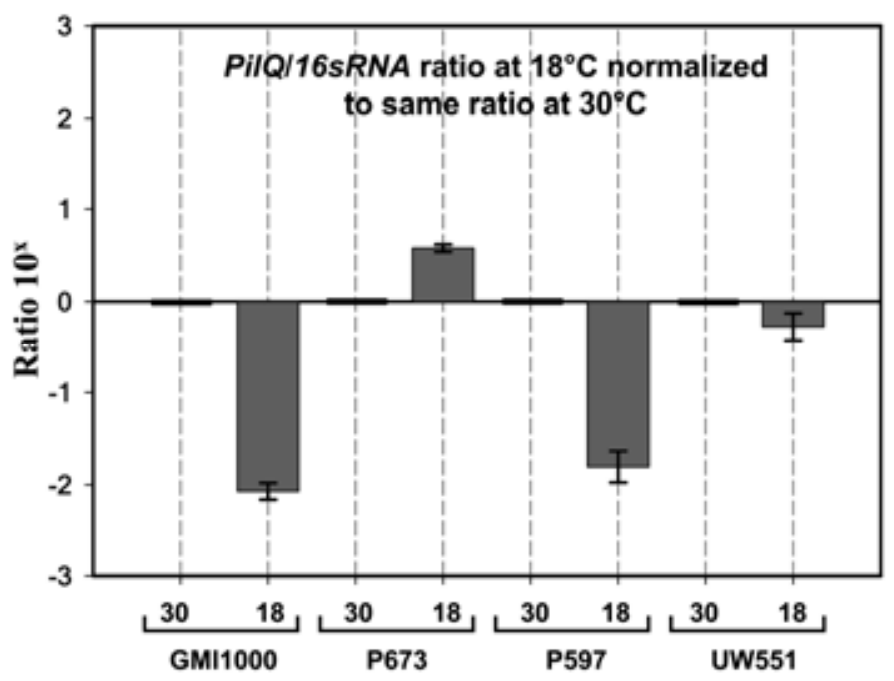

Fig. 6. Relative expression of pilQ for GMI100, P673, P597, and UW551 at $18^{\circ} \mathrm{C}$. Quantitative reverse transcription-polymerase chain reaction was performed on equal amounts of total RNA per sample extracted from bacterial suspensions grown in co-culture with in vitro tomato seedlings. 16sRNA was used as reference for the relative expression ratio calculation. This ratio at $18^{\circ} \mathrm{C}$ was further normalized using the same ratio at $30^{\circ} \mathrm{C}$ as reference for each strain. Bars represent standard deviation. sequenced and are publicly available $(13,36)$, facilitating further genetic analysis of the nonsequenced strains.

We determined that there is an important barrier at the root colonization level in the infection process because nonpathogenic strains at $18^{\circ} \mathrm{C}$ did not penetrate and colonize the plants, despite being able to multiply, move, and even cause wilt when inoculated in the stem. This ability to invade and move within the host without causing disease at low temperature is variable for different strains. The causes for this variation are unknown to date, however are potentially dependent on several factors including density, host resistance, fitness, and mobility $(3,38)$. In this study, P597 and GMI1000 did not recover the full virulence potential displayed at higher temperature when inoculated in the stem, suggesting that there are other virulence factors dependent on temperature at later stages of the disease.

An important factor that may be affecting the ability of specific $R$. solanacearum strains to colonize and invade the host roots at low temperatures is the comparative fitness of such strains at different temperatures. Fitness is a complex characteristic and cannot fully be described by one model; however, the growth rate of bacteria in culture medium is a commonly used model for evaluating reproductive fitness (32). Analyses of in vitro growth at $18^{\circ} \mathrm{C}$ of the cool virulent strains P673 and UW551 in either NB or MM media compared with the nonpathogenic strains GMI1000 and P597 showed no significant differential impact of temperature on final bacterial density or on growth rate. In previous studies in vitro growth of GMI1000 and UW551 in MM was compared at two temperatures with similar results (27). Additional experiments measuring growth of $R$. solanacearum in co-cultures with tomato seedlings grown in vitro in Murashige-Skoog media plus sucrose did not provide different results.

Our current hypothesis is that twitching contributes to movement and attachment to host roots at the sites of penetration, usually lateral roots bases (20). Attenuation or lack of twitching might constitute a contributing factor to loss of virulence at low temperatures. To the best of our knowledge, twitching motility of $R$. solanacearum has not been characterized at temperatures lower than $20^{\circ} \mathrm{C}$ until this work. Comparison of visually assessed twitching motility of actively growing colonies on NAS plates showed that the cool virulent strains maintained a similar level of twitching motility at both temperatures $\left(30\right.$ and $\left.18^{\circ} \mathrm{C}\right)$, while there was an observable attenuation of the activity at $18^{\circ} \mathrm{C}$ for the nonpathogenic strains. During the first stages of colony growth, the differences were clear, becoming less noticeable at higher colony densities. In order to assess possible effects of tomato roots on bacterial twitching, the in vitro experiments were modified by incubating bacterial populations of each strain in cocultures with in vitro tomato seedlings at 30 and $18^{\circ} \mathrm{C}$ prior to plating them on NAS or MM (data not shown). These additional experiments did not provide a clear distinction between twitching level activity between temperatures, because the suspensions were not diluted, thus individual colonies were more difficult to distinguish visually.

The observation of colonies is a crude tool to assess differences in twitching activity unless there is a drastic difference such as the one we observed when we compared plates incubated on NAS with MM. Using pilQ as a marker to evaluate the relative expression of the twitching activity of $R$. solanacearum strains provided us with a sensitive and quantifiable method of comparison. For this experiment the samples were obtained from bacterial suspensions previously incubated in co-culture with in vitro tomato roots. This experimental design is more similar to the natural rhizosphere environment conducive to infection than the in vitro tests on solid media plates. The cool virulent strains (P673 and UW551) maintained a similar level of pilQ expression at both temperatures, while for the nonpathogenic ones (P597 and GMI1000) downregulated pilQ expression at the low temperature (Fig. 6). These results and the previous experiments of twitching 
activity on growing colonies in vitro suggest that there is a correlation between cool virulence and level of twitching activity. The nature of this correlation is unknown. We hypothesize that temperature could affect directly the Tpf system through differences in genes present or not in certain group of strains, horizontally transfer to strains that share the same niches, or most likely, indirectly through one of the known or unknown regulatory systems present in the $R$. solanacearum genome.

In our experiments we observed that temperature affects virulence of the strains at the stage of root colonization and invasion. At later stages when the pathogen has invaded the vascular vessels, the effects might be of a different nature. Since the regulatory system of $R$. solanacearum is very complex, possibly a high throughput approach and a specific target, such as looking at the root attachment and colonization early stage of the infection only, would allow a better understanding of the many factors that might be contributing to virulence at low temperatures. Currently, works on proteomics profiles of the four studied strains when in contact with tomato roots are in progress in order to identify candidate factors that may contribute to differences in virulence at low temperatures.

\section{ACKNOWLEDGMENTS}

This research was funded by the USDA Floral Industry Task Force Specific Cooperative Agreement, The Fred C. Gloeckner Foundation, and the University of Florida Institute of Food and Agricultural Sciences. We thank C. Allen at the University of Wisconsin; the Belgian Coordinated Collections of Micro-Organisms, Brussels, Belgium; and P. Prior, of the Station of Vegetable Pathology, INRA, CIRAD, UMR PVBMT, Saint Pierre, La Réunion, for providing us with $R$. solanacearum strains from different origins for our study and for identifying the sequevars of strains P673 and P597. We thank S. Arthurs for critical review of the manuscript.

\section{LITERATURE CITED}

1. Agrios, G. N. 1969. Plant Pathology. 4th ed. Academic Press, San Diego, CA.

2. Bos, L., and Parlevliet, J. E. 1995. Concepts and terminology on plant/ pest relationships: Toward consensus in plant pathology and crop protection. Pages 69-102 in: Annual Review of Phytopathology. Annual Reviews Inc., Palo Alto, CA.

3. Brown, D. G., and Allen, C. 2004. Ralstonia solanacearum genes induced during growth in tomato: An inside view of bacterial wilt. Mol. Microbiol. 53:1641-1660.

4. Buddenhagen, I., and Kelman, A. 1964. Biological and physiological aspects of bacterial wilt caused by Pseudomonas solanacearum. Annu. Rev. Phytopathol. 2:203-230.

5. Buddenhagen, I., Sequeira, L., and Kelman, A. 1962. Designation of races in Pseudomonas solanacearum. Phytopathology 52:726-1962.

6. Ciampi, L., and Sequeira, L. 1980. Influence of temperature on virulence of race 3 strains of Pseudomonas-solanacearum. Am. Potato J. 57:307317.

7. Clough, S. J., Schell, M. A., and Denny, T. P. 1994. Evidence for involvement of a volatile extracellular factor in Pseudomonas solanacearum virulence gene-expression. Mol. Plant-Microbe Interact. 7:621-630.

8. Drigues, P., Demery-Lafforgue, D., Trigalet, A., Dupin, P., Samain, D., and Asselineau, J. 1985. Comparative studies of lipopolysaccharide and exopolysaccharide from a virulent strain of Pseudomonas solanacearum and from three avirulent mutants. J. Bacteriol. 162:504-509.

9. Elphinstone, J. G. 2005. The current bacterial wilt situation: A global overview. Pages 9-28 in: Bacterial Wilt Disease and the Ralstonia solanacearum Species Complex. P. P. C. Allen and A. C. Hayward, eds. American Phytopathological Society, St. Paul, MN.

10. Fegan, M., and Prior, P. 2005. How complex is the "Ralstonia solanacearum species complex". Pages 449-462 in: Bacterial Wilt Disease and the Ralstonia solanacearum Species Complex. P. P. C. Allen and A. C. Hayward, eds. The American Phytopathological Society, St. Paul, MN.

11. Fegan, M., and Prior, P. 2006. Diverse members of the Ralstonia solanacearum species complex cause bacterial wilts of banana. Austral. Plant Pathol. 35:93-101.

12. Frey, P., Smith, J. J., Albar, L., Prior, P., Saddler, G. S., Trigalet-Demery, D., and Trigalet, A. 1996. Bacteriocin typing of Burkholderia (Pseudomonas) solanacearum race 1 of the French West Indies and correlation with genomic variation of the pathogen. Appl. Environ. Microbiol. 62:473-479.

13. Gabriel, D. W., Allen, C., Schell, M., Denny, T. P., Greenberg, J. T., Duan, Y. P., Flores-Cruz, Z., Huang, Q., Clifford, J. M., Presting, G., Gonzalez, E. T., Reddy, J., Elphinstone, J., Swanson, J., Yao, J., Mulholland, V., Liu, L., Farmerie, W., Patnaikuni, M., Balogh, B., Norman, D., Alvarez, A., Castillo, J. A., Jones, J., Saddler, G., Walunas, T., Zhukov, A., and Mikhailova, N. 2006. Identification of open reading frames unique to a select agent: Ralstonia solanacearum race 3 biovar 2. Mol. Plant-Microbe Interact. 19:69-79. doi: 10.1094/MPMI-19-0069.

14. Hayward, A. C. 1964. Characteristics of Pseudomonas solanacearum. J. Appl. Microbiol. 27:265-277. doi:10.1111/j.1365-2672.1964.tb04912.x.

15. Hayward, A. C. 1991. Biology and epidemiology of bacterial wilt caused by Pseudomonas solanacearum. Annu. Rev. Phytopathol. 29:65-87.

16. He, L. Y., Sequeira, L., and Kelman, A. 1982. Characteristics of strains of Pseudomonas-solanacearum from China. Phytopathology 72:936.

17. Jacobs, J. M., Meng, F., Babujee, L., and Allen, C. 2009. Comparative gene expression profile analysis of temperate and tropical strains of Ralstonia solanacearum. (Abstr.) Phytopathology 99(Suppl.):S57-S58.

18. Janse, J. D., Van Den Beld, H. E., Elphinstone, J., Simpkins, S., TjouTam-Sin, N. N. A., and Van Vaerenbergh, J. 2004. Introduction to Europe of Ralstonia solanacearum biovar 2, race 3 in Pelargonium zonale cuttings. J. Plant Pathol. 86:147-155.

19. Jaunet, T. X., and Wang, J. F. 1999. Variation in genotype and aggressiveness of Ralstonia solanacearum race 1 isolated from tomato in Taiwan. Phytopathology 89:320-327.

20. Kang, Y., Liu, H., Genin, S., Schell, M. A., and Denny, T. P. 2002. Ralstonia solanacearum requires type 4 pili to adhere to multiple surfaces and for natural transformation and virulence. Mol. Microbiol. 46:427-437.

21. Kim, S. H., Olson, T. N., and Schaad, N. W. 2002. Ralstonia solanacearum biovar 2, race 3 in geraniums imported from Guatemala to Pennsylvania in 1999. (Abstr.) Phytopathology 92(suppl.):S42.

22. Kim, S. H., Olson, T. N., Schaad, N. W., and Moorman, G. W. 2003. Ralstonia solanacearum race 3, biovar 2, the causal agent of brown rot of potato, identified in geraniums in Pennsylvania, Delaware, and Connecticut. Plant Dis. 87:450.

23. Lambert, C. D. 2002. Agricultural Bioterrorism Protection Act of 2002: Possession, Use, and Transfer of Biological; Agents and Toxins; Interim and Final Rule. (7 CFR Part 331). Federal Register 67:76908-76938.

24. Liu, H., Kang, Y., Genin, S., Schell, M. A., and Denny, T. P. 2001. Twitching motility of Ralstonia solanacearum requires a type IV pilus system. Microbiology 147:3215-3229.

25. Marin, J. E., and El-Nashaar, H. M. 1993. Pathogenicity of the New Phenotypes of Pseudomonas solanacearum from Peru. Pages 78-84 in: ACIAR Proc.; Bacterial Wilt. G. L. Hartman and A. C. Hayward, eds. ACIAR (Australian Centre for International Agricultural Research), Canberra, ACT, Australia.

26. Mattick, J. S. 2002. Type IV pili and twitching motility. Annu. Rev. Microbiol. 56:289-314.

27. Meng, F., Milling, A., and Allen, C. 2008. Interactions with hosts at cool temperature, not cold tolerance, explain the unique epidemiology of Ralstonia solanacearum race 3 biovar 2. (Abstr.) Phytopathology 98(suppl.):S104.

28. Milling, A., Meng, F. H., Denny, T. P., and Allen, C. 2009. Interactions with hosts at cool temperatures, not cold tolerance, explain the unique epidemiology of Ralstonia solanacearum race 3 biovar 2. Phytopathology 99:1127-1134.

29. Norman, D. J., Huang, Q., Yuen, J. M. F., Mangravita-Novo, A., and Byrne, D. 2009. Susceptibility of geranium cultivars to Ralstonia solanacearum. Hortscience 44:1504-1508.

30. Norman, D. J., Zapata, M., Gabriel, D. W., Duan, Y. P., Yuen, J. M. F., Mangravita-Novo, A., and Donahoo, R. S. 2009. Genetic diversity and host range variation of Ralstonia solanacearum strains entering North America. Phytopathology 99:1070-1077.

31. Pastrik, K. H., Elphinstone, J. G., and Pukall, R. 2002. Sequence analysis and detection of Ralstonia solanacearum by multiplex PCR amplification of 16S-23S ribosomal intergenic spacer region with internal positive control. Eur. J. Plant Pathol. 108:831-842.

32. Pope, C. F., Mchugh, T. D., and Gillespie, S. H. 2010. Methods to determine fitness in bacteria. Methods Mol. Biol. 642:113-121. doi:10.1007/978-1-60327-279-7_9.

33. Prior, P., and Fegan, M. 2005. Recent developments in phylogeny and classification of Ralstonia solanacearum. Pages 127-136 in: First International Symposium on Tomato Diseases. M. T. Momol, P. Ji, and J. B. Jones, eds. Acta Hort., Orlando, FL.

34. Prior, P., and Steva, H. 1990. Characteristics of strains of Pseudomonassolanacearum from the French West Indies. Plant Dis. 74:13-17.

35. Remenant, B., Coupat-Goutaland, B., Guidot, A., Cellier, G., Wicker, E., Allen, C., Fegan, M., Pruvost, O., Elbaz, M., Calteau, A., Salvignol, G., 
Mornico, D., Mangenot, S., Barbe, V., Medigue, C., and Prior, P. 2010. Genomes of three tomato pathogens within the Ralstonia solanacearum species complex reveal significant evolutionary divergence. BMC Genom. 11:Article No. 379

36. Salanoubat, M., Genin, S., Artiguenave, F., Gouzy, J., Mangenot, S., Arlat, M., Billault, A., Brottier, P., Camus, J. C., Cattolico, L., Chandler, M., Choisne, N., Claudel-Renard, C., Cunnac, S., Demange, N., Gaspin, C., Lavie, M., Moisan, A., Robert, C., Saurin, W., Schiex, T., Siguier, P., Thebault, P., Whalen, M., Wincker, P., Levy, M., Weissenbach, J., and Boucher, C. A. 2002. Genome sequence of the plant pathogen Ralstonia solanacearum. Nature 415:497-502.

37. Schell, M. A. 1987. Purification and characterization of an endoglucanase from Pseudomonas solanacearum. Appl. Environ. Microbiol. 53:22372241.

38. Schell, M. A. 2000. Control of virulence and pathogenicity genes of Ralstonia solanacearum by an elaborate sensory network. Annu. Rev. Phytopathol. 38:263-292.

39. Schell, M. A., Roberts, D. P., and Denny, T. P. 1988. Analysis of the Pseudomonas solanacearum polygalacturonase encoded by pglA and its involvement in phytopathogenicity. J. Bacteriol. 170:4501-4508.

40. Swanepoel, A. E., and Young, B. W. 1988. Characteristics of south African strains of Pseudomonas-solanacearum. Plant Dis. 72:403-405.

41. Swanson, J. K., Montes, L., Mejia, L., and Allen, C. 2007. Detection of latent infections of Ralstonia solanacearum race 3 biovar 2 in geranium. Plant Dis. 91:828-834.

42. Swanson, J. K., Yao, J., Tans-Kersten, J., and Allen, C. 2005. Behavior of Ralstonia solanacearum race 3 biovar 2 during latent and active infection of geranium. Phytopathology 95:136-143.
43. Tans-Kersten, J., Huang, H., and Allen, C. 2001. Ralstonia solanacearum needs motility for invasive virulence on tomato. J. Bacteriol. 183:35973605.

44. Thurston, H. D. 1963. Bacterial wilt of potatoes in Colombia. Am. Potato J. 40:381-390.

45. Van Elsas, J. D., Kastelein, P., Van Bekkum, P., Van Der Wolf, J. M., De Vries, P. M., and Van Overbeek, L. S. 2000. Survival of Ralstonia solanacearum biovar 2, the causative agent of potato brown rot, in field and microcosm soils in temperate climates. Phytopathology 90:1358-1366.

46. Wicker, E., Grassart, L., Coranson-Beaudu, R., Mian, D., Guilbaud, C., Fegan, M., and Prior, P. 2007. Ralstonia solanacearum strains from Martinique (French west indies) exhibiting a new pathogenic potential. Appl. Environ. Microbiol. 73:6790-6801.

47. Williamson, L., Nakaho, K., Hudelson, B., and Allen, C. 2002. Ralstonia solanacearum race 3, biovar 2 strains isolated from geranium are pathogenic on potato. Plant Dis. 86:987-991.

48. Yabuuchi, E., Kosako, Y., Yano, I., Hotta, H., and Nishiuchi, Y. 1995. Transfer of two Burkholderia and an Alcaligenes species to Ralstonia gen. Nov.: Proposal of Ralstonia pickettii (Ralston, Palleroni and Doudoroff 1973) comb. Nov., Ralstonia solanacearum (Smith 1896) comb. Nov. and Ralstonia eutropha (Davis 1969) comb. Nov. Microbiol. Immunol. 39:897-904.

49. Yao, J., and Allen, C. 2006. Chemotaxis is required for virulence and competitive fitness of the bacterial wilt pathogen Ralstonia solanacearum. J. Bacteriol. 188:3697-3708.

50. Yao, J., and Allen, C. 2007. The plant pathogen Ralstonia solanacearum needs aero taxis for normal biofilm formation and interactions with its tomato host. J. Bacteriol. 189:6415-6424. 